\title{
Protective Effect of Plumeria obtusa Leaves Extracts on Dexamethasone-induced Insulin-resistance Diabetes Mellitus in Rats
}

\author{
Sumeet Gupta ${ }^{1, *}$, Hitendra Sharma1, Mohamed Aly Morsy ${ }^{2,3}$, Anroop Balachandran Nair ${ }^{2}$, Kamalpreet \\ Kaur ${ }^{1}$, Satish Kumar', Meenakshi Dhanawat ${ }^{1}$
}

1Department of Pharmacology, MM College of Pharmacy, MM (Deemed to be University), Mullana, Ambala, Haryana, INDIA. ${ }^{2}$ Department of Pharmaceutical Sciences, College of Clinical Pharmacy, King Faisal University, Al-Ahsa, SAUDI ARABIA.

${ }^{3}$ Department of Pharmacology, Faculty of Medicine, Minia University, El-Minia, EGYPT.

\begin{abstract}
Background: Plumeria obtusa L., a potential medicinal plant, is still unexplored for its anti-diabetic effect. The objective of this study was to examine the protective effect of Plumeria obtusa leaves extracts on insulin-resistance diabetic rat model. Materials and Methods: Male Wistar rats were distributed into twelve groups. Dexamethasone was used to induce insulin-resistance diabetes mellitus. Three different doses of each extract (petroleum ether, ethanol and aqueous) were orally administered for 45 days. Biochemical estimations, as well as histological and scanning electron microscopy examinations, were done on the $45^{\text {th }}$ day. Results: Statistically significant improvement in serum levels of glucose, glycosylated haemoglobin and insulin, as well as lipid profiles, were observed specifically with ethanol and aqueous extracts in comparison to the positive control group. Conclusion: The histological and scanning electronic microscopy studies revealed a significant improvement in various organs. Hence, this plant needs to be explored at the molecular level.
\end{abstract}

Key words: Plumeria obtusa, Insulin-resistance diabetes mellitus, Lipid profile, Insulin, Scanning electron microscopy.

\section{INTRODUCTION}

Diabetes mellitus is a very common lifestyle disease with metabolic disturbance leads to a deficiency of insulin secretion or insulin does not work properly in the body. ${ }^{1,2}$ It is already proved that there are multiple factors exist to aggravate the complications, which include diabetic nephropathy, diabetic neuropathy and diabetic retinopathy. ${ }^{3,4}$ According to the recent report available, about 422 million people have diabetes globally and maximum people arise from low- and middle-income countries. ${ }^{5}$ China has the highest prevalence record (98.4 million) with diabetes mellitus followed by India; the second-highest prevalence with 64 million affects adults. The situation is at an alarming stage for the last 5 years and it may increase by $25 \%$ in 2030 on the global population. ${ }^{5,6}$
Various molecular pathways are implicated in the body, which may aggravate diabetes mellitus. Insulin shows sympathoexcitatory and vasodilator effects by unknown mechanisms. Insulin resistance in type 2 diabetes mellitus is not merely associated with hyperglycaemia but even with hyperlipidaemia and atherosclerosis. Glucocorticoids can hinder the ability of insulin to control food intake by varying insulin-induced central neural peptide as well as release of neurotransmitter. ${ }^{7}$ The main cause of complications of diabetes mellitus is high-end blood glucose levels in the form of sorbitol in the body. Reactive oxygen species induce a complexing agent called advanced glycation end-product (AGE), which may convert normal glucose level stage to hyper glucose level stage.
Submission Date: 25-11-2020; Revision Date: 18-12-2020; Accepted Date: 21-02-2021

DOI: 10.5530/ijper.55.1s.49 Correspondence: Dr. Sumeet Gupta Professor, Department of Pharmacology, MM College of Pharmacy, M. M. University (Deemed to be University) (Deemed to be University), Mullana, (Ambala), Haryana, INDIA. Phone no: +919872620252 Email: sumeetgupta25@ gmail.com

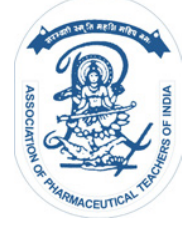

www.ijper.org 
Moreover, $\beta$-cell dysfunction and insulin resistance show a link with the same pathway. Reactive oxygen species and hyperglycaemia could activate JNK/SAPK, NF- $x \mathrm{~B}$, p38 MAPK and hexosamine pathways. ${ }^{8}$ These are stress-sensitive signalling pathways which participate in the development of diabetes mellitus. Genetics play an important role in the occurrence of type 2 diabetes mellitus. Other factors like deficiencies in the insulinsignalling pathway due to mutations in specific insulin receptor and the existence of antibodies to the insulin or insulin receptor can also cause insulin resistance.

Treatment of diabetes with complimentary herbal medicines seems to be promising as they show reduced side effects of conventional drugs as well as helps in reducing the complications associated with diabetes. ${ }^{10}$ Thus, herbal and natural medicines and, in particular, plants are a valuable source in the management of diabetes. ${ }^{11-13}$ Plumeria obtusa L. is a plant that belongs to the family Apocynaceae, which have a number of species reported. It is widely cultivated in India. The two species Plumeria obtusa and Plumeria pudica are evergreen and are suitable for a warm climate. ${ }^{14}$ Plumeria obtusa and Plumeria pudica have been ornamentally and medicinally used. Plumeria obtusa is well known for other pharmacological effects like anti-inflammatory, antimicrobial, antipyretic and anti-diarrheal, as well as treatment for bronchitis, tumour and asthma. ${ }^{15}$ It is a small shrub with a height of 0.9 to $6 \mathrm{~m}$ and a leaf length is $6-22 \mathrm{~cm}$. Plumeria obtusa flowers secrete several volatile components that have found various applications including the perfume industry to provide fragrance. ${ }^{16}$

Two species of Apocynaceae family; Plumeria rubra and Plumeria alba Linn showed an excellent anti-diabetic activity on streptozotocin-induced diabetic rats. ${ }^{17,18}$ Leaves of Plumeria obtusa were reported traditionally to have antidiabetic activity in South Africa by Bapedi traditional healers. ${ }^{19}$ Studies revealed the presence of triterpenoids, glucosides, flavonoids and a higher amount of tannins in Plumeria obtusa. ${ }^{15,20}$ However, the literature suggests that no studies have been carried out to assess the clinical potential of Plumeria obtusa in the management of diabetes mellitus. Taking consideration of claimed activities of species of this plant, this study evaluated the antidiabetic effect of Plumeria obtusa leaves extracts against insulin-resistance diabetic rat model.

\section{MATERIALS AND METHODS}

\section{Drugs and chemicals}

Dexamethasone sodium phosphate was obtained as a gift sample from Zydus Cadila (Ahmedabad, Gujarat, India) and metformin from Torrent Pharmaceuticals
(Ahmedabad, Gujarat, India). All other solvents and chemicals used were of the highest grade.

\section{Plant material}

Leaves of Plumeria obtusa L. were procured in September from the main botanical garden of Kurukshetra University (Kurukshetra, Haryana, India). Leaves were identified and deposit the plantleaf sample in the National Institute of Science Communication and Information Resources (NISCAIR; New Delhi, India) with Ref. NISCAIR/RHMD/Consult/-2011-12/1866/166.

\section{Preparation of extracts}

The plant leaves were collected and washed using distilled water to eliminate debris then dried in an oven for 10 days, where the temperature is maintained at $35-40^{\circ} \mathrm{C}$. The leaves were then minced using a grinder and the fine particles were sieved (sieve \# 60 ) and collected in a polythene bag and stored for further use. The dried powder of leaves $(3 \mathrm{~kg})$ was sequentially extracted using petroleum ether and ethanol consecutively for $72 \mathrm{hr}$ each in a Soxhlet apparatus. The residual solvents were eliminated by vacuum drying. Crude aqueous extract of these dried powder materials was freshly prepared separately by maceration for $24 \mathrm{hr}$. The extracts obtained were stored at low temperature (below $4^{\circ} \mathrm{C}$ ) for further use.

\section{Animals}

Adult male Wistar rats (200-250 g) were procured from the approved animal house at the National Institute of Pharmaceutical Education and Research (Punjab, India). The experimental protocol was accepted by the Institute from Animal Ethics Committee (MMCP/IEC/11/02). The animals were housed in an animal house under a specific pathogen-free condition in a controlled laboratory environment (temperature of $24-28^{\circ} \mathrm{C}$ and relative humidity of $60-70 \%$ with a $12 \mathrm{hr}$ day and night cycle. Rats were fed with a standard pellet diet and were accessed to water during the whole experiment. Preassessment of glucose levels was studied on normal rats with all three extracts (petroleum ether, ethanol and aqueous extract) at a precise dose of $50 \mathrm{mg} / \mathrm{kg}$ for 15 days of treatment. After a washout period for 15 days, the rats were again reused.

\section{Experimental design}

Rats were again divided into 12 groups; each contains 6 rats. Group 1 (negative control): Oral saline, Group

2 (positive control): Dexamethasone $(10 \mathrm{mg} / \mathrm{kg}$, s.c. every alternative day for 45 days) ${ }^{21}$ to induce insulinresistance diabetes mellitus, Group 3 (standard control): Dexamethasone + Metformin (200 mg/kg once daily, 
oral), Groups 4, 5, 6 (petroleum ether extract groups): Dexamethasone + Plumeria obtusa petroleum ether extract $(100,200,400 \mathrm{mg} / \mathrm{kg}$, once daily, oral), Groups 7, 8, 9 (ethanol extract groups): Dexamethasone + Plumeria obtusa ethanol extract $(100,200,400 \mathrm{mg} / \mathrm{kg}$, once daily, oral), Groups 10, 11, 12 (aqueous extract groups): Dexamethasone + Plumeria obtusa aqueous extract (100, 200, $400 \mathrm{mg} / \mathrm{kg}$, once daily, oral).

\section{Biochemical estimations}

Blood samples were drawn on $0,7^{\text {th }}, 14^{\text {th }}, 21^{\text {st }}$ and $45^{\text {th }}$ day. The rats were anaesthetized ${ }^{22}$ and blood sampling was done by retro-orbital bleeding. About $30 \mu \mathrm{l}$ serum was then taken separately to determine glucose, triglyceride, high-density lipoproteins and low-density lipoproteins. Serum insulin was analyzed by a radioimmunoassay kit supplied by Stat Diagnostics (Mumbai, Maharashtra, India). Glycosylated haemoglobin levels were estimated using the standard technique. ${ }^{23}$

\section{Histological studies and scanning electron microscopy}

At the end of the experiment ( $45^{\text {th }}$ day), three rats from each group were sacrificed under anaesthesia using pentobarbitone sodium $(60 \mathrm{mg} / \mathrm{kg})^{22}$ and further by cervical dislocation if necessary. Various organs were used for histopathology and scanning electron microscopy. ${ }^{24}$ The remaining animals are transferred to the rehabilitation room of our animal house for proper treatment and extra care.

\section{Statistical analysis}

The data presented in the tables/figures are the mean \pm standard deviation (SD). The statistical difference between mean was analysed using ANOVA and by Tukey's multiple comparison test. The $P$ value less than 0.05 was considered as significant.

\section{RESULTS}

\section{Biochemical parameters and body weights}

Statistically significant variations in the blood glucose levels (Figure 1) were witnessed after the $14^{\text {th }}$ day of the treatment with ethanol and aqueous extracts at two specific doses $(200 \mathrm{mg} / \mathrm{kg}$ and $400 \mathrm{mg} / \mathrm{kg}$ ) whereas the petroleum ether extract-treated group shown a statistically significant reduction with only one dose (400 $\mathrm{mg} / \mathrm{kg}$ ) at the same time interval when compared with the positive control group.

On the $45^{\text {th }}$ day (end of the treatment), high-density lipoproteins levels of ethanol as well as aqueous extract treated-groups shown a statistically significant increase when compared with the positive control group. The

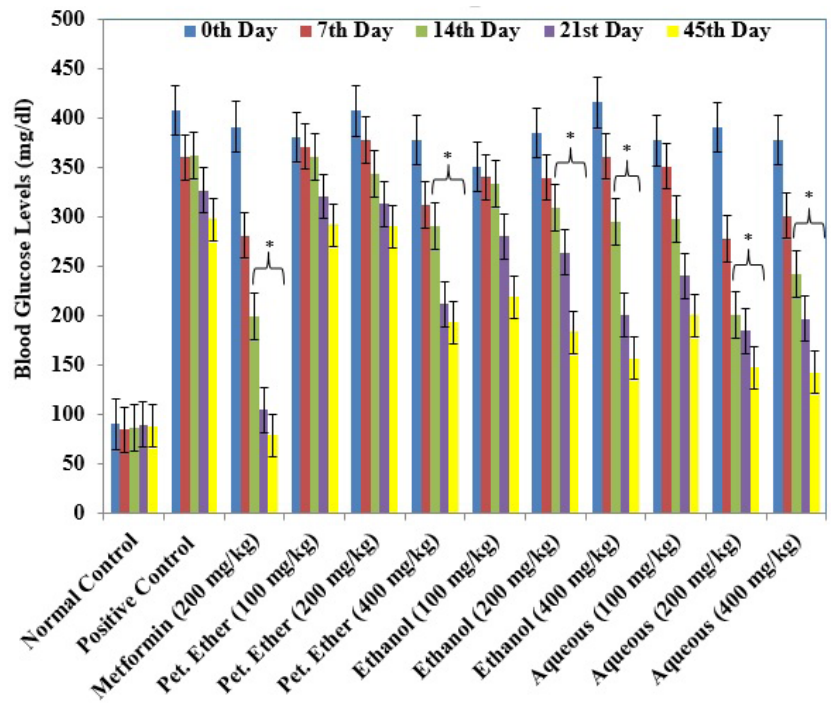

Figure 1: Effect of Plumeria obtusa leaves extracts on blood glucose levels at different time intervals in insulin-resistance diabetic rats.

Pet Ether: Petroleum ether.

triglycerides levels were reduced statistically significant after treatment of two extracts (ethanol and aqueous) by three tested doses whereas the petroleum ether extracttreated group showed a statistically significant reduction with only the highest dose $(400 \mathrm{mg} / \mathrm{kg})$. The levels of low-density lipoproteins reduced only with the treatment of aqueous extract groups when the results are compared with the positive control group (Table 1).

Insulin levels were reduced considerably after treatment with aqueous and ethanol extracts, when the values are compared with the positive control group (Table 1). Both aqueous and ethanol extracts shown a statistically significant reduction in glycosylated haemoglobin compared to the positive control group, whereas the petroleum ether extract-treated group showed a significant reduction only at $400 \mathrm{mg} / \mathrm{kg}$.

Insignificant changes in body weights were observed in the first week of treatments. The aqueous extracts and the highest dose of ethanol extract can significantly reduce body weights but only in the second week of treatments (Table 2).

\section{Histopathology}

Liver

The hepatic cells (Figure 2A1) of normal liver were good in morphology and clearly demonstrated the cytoplasm, nucleus, nucleolus and central vein whereas, in the insulin-resistance diabetic rat group (Figure 2B1), tissue section showed alteration in the arrangement of hepatic cells with dilated sinusoids, periportal fatty infiltration with focal necrosis and predominantly inflammatory cells were seen. The standard-treated group 
Table 1: Effect of leaf extracts of Plumeria obtusa on serum lipid profile, insulin level and glycosylated haemoglobin at the $45^{\text {th }}$ day in insulin-resistance diabetic rat model.

\begin{tabular}{|c|c|c|c|c|c|}
\hline Groups & $\begin{array}{c}\text { HDL } \\
\text { (mg/dl) }\end{array}$ & $\begin{array}{l}\text { Triglycerides } \\
\text { (mg/dl) }\end{array}$ & $\begin{array}{c}\text { LDL } \\
\text { (mg/dl) }\end{array}$ & $\begin{array}{l}\text { Insulin } \\
(\mu \mathrm{g} / \mathrm{ml})\end{array}$ & $\begin{array}{c}\text { Glycosylated } \\
\text { Haemoglobin (\%) }\end{array}$ \\
\hline Normal Control & $40.7 \pm 5.2^{* * *}$ & $89.1 \pm 6.08^{* * *}$ & $93.1 \pm 16.9^{* * *}$ & $14.0 \pm 0.89^{* * *}$ & $5.2 \pm 1.3^{* * *}$ \\
\hline Positive Control & $19.81 \pm 6.67$ & $220.7 \pm 21.5$ & $190.6 \pm 26.3$ & $26.95 \pm 2.8$ & $11.5 \pm 1.5$ \\
\hline Metformin $(200 \mathrm{mg} / \mathrm{kg})$ & $42.6 \pm 4.10^{* * *}$ & $109.6 \pm 6.53^{* * *}$ & $71.2 \pm 22.8^{* * *}$ & $14.8 \pm 2.4^{* * *+}$ & $4.9 \pm 1.0^{* * *}$ \\
\hline Pet. Ether $(100 \mathrm{mg} / \mathrm{kg})$ & $23.0 \pm 4.41$ & $193.1 \pm 7.17$ & $184.2 \pm 32.7$ & $23.9 \pm 3.0$ & $11.3 \pm 1.4$ \\
\hline Pet. Ether $(200 \mathrm{mg} / \mathrm{kg})$ & $23.1 \pm 4.31$ & $195.9 \pm 16.52$ & $182.4 \pm 28.1$ & $29.5 \pm 2.65$ & $11.3 \pm 1.5$ \\
\hline Pet. Ether $(400$ mg/kg) & $25.0 \pm 2.86$ & $188.5 \pm 7.50^{*}$ & $176.3 \pm 16.3$ & $22.88 \pm 2.9$ & $8.3 \pm 1.6^{*}$ \\
\hline Ethanol $(100 \mathrm{mg} / \mathrm{kg})$ & $30.3 \pm 4.21^{* *}$ & $179.0 \pm 8.58^{* * *}$ & $165.7 \pm 21.7$ & $22.0 \pm 3.4$ & $9.1 \pm 1.9$ \\
\hline Ethanol $(200 \mathrm{mg} / \mathrm{kg})$ & $31.7 \pm 4.5^{* * *}$ & $163.1 \pm 6.20^{* * *}$ & $160.0 \pm 24.0$ & $19.6 \pm 2.8^{* * *}$ & $8.0 \pm 1.3^{* *}$ \\
\hline Ethanol $(400 \mathrm{mg} / \mathrm{kg})$ & $36.6 \pm 3.02^{* * *}$ & $152.1 \pm 19.1^{* * * *}$ & $142.1 \pm 21.9$ & $16.8 .0 \pm 1.4^{* * * *}$ & $7.3 \pm 1.8^{* * *}$ \\
\hline Aqueous $(100 \mathrm{mg} / \mathrm{kg})$ & $27.4 \pm 2.31$ & $153.6 \pm 21.4^{* * *}$ & $132.4 \pm 12.5^{* *}$ & $20.2 \pm 4.9^{* *}$ & $8.5 \pm 1.5^{*}$ \\
\hline Aqueous (200 mg/kg) & $37.6 \pm 3.86^{* * *}$ & $141.1 \pm 13.9^{* * *}$ & $134.6 \pm 21.1^{*}$ & $15.3 \pm 1.2^{* * *}$ & $7.0 \pm 1.4^{* * *}$ \\
\hline Aqueous (400 mg/kg) & $43.6 \pm 2.98^{* * *}$ & $130.3 \pm 21.1^{* * *}$ & $127.5 \pm 43.7^{* *}$ & $14.5 \pm 1.4^{* * *}$ & $6.8 \pm 1.2^{* * *}$ \\
\hline
\end{tabular}

Statistical analysis of data was carried by one-way ANOVA followed by Tukey's Multiple Range Test. The values are mean \pm SD for each group ( $n=6$ ). $P$ value less than 0.05 was considered significant. Pet. Ether: Petroleum ether. *** $P<0.001, * * P<0.01, * P<0.05$.

\begin{tabular}{|c|c|c|c|c|c|}
\hline \multirow{2}{*}{ Groups } & \multicolumn{5}{|c|}{ Body weight (g) } \\
\hline & $0^{\text {th }}$ day & $7^{\text {th }}$ day & $14^{\text {th }}$ day & $21^{\text {st }}$ day & $45^{\text {th }}$ day \\
\hline Normal Control & $165 \pm 7.0$ & $160 \pm 9.7$ & $162 \pm 10.4^{* *}$ & $167 \pm 11.3$ & $164 \pm 7.4$ \\
\hline Positive Control & $169 \pm 8.6$ & $174 \pm 6.3$ & $189 \pm 12.5$ & $175 \pm 18.3$ & $172 \pm 18.8$ \\
\hline Metformin $(200 \mathrm{mg} / \mathrm{kg})$ & $172 \pm 10.6$ & $176 \pm 9.2$ & $184 \pm 7.4$ & $189 \pm 11.3$ & $194 \pm 18.3$ \\
\hline Pet. Ether $(100 \mathrm{mg} / \mathrm{kg})$ & $164 \pm 14.7$ & $168 \pm 5.6$ & $175 \pm 12.4$ & $177 \pm 10.0$ & $174 \pm 11.3$ \\
\hline Pet. Ether $(200 \mathrm{mg} / \mathrm{kg})$ & $159 \pm 16.8$ & $165 \pm 6.4$ & $170 \pm 6.5$ & $177 \pm 7.5$ & $174 \pm 10.3$ \\
\hline Pet. Ether $(400$ mg/kg) & $165 \pm 10.4$ & $162 \pm 8.3$ & $169 \pm 7.4$ & $173 \pm 10.4$ & $167 \pm 6.4$ \\
\hline Ethanol $(100 \mathrm{mg} / \mathrm{kg})$ & $170 \pm 11.5$ & $174 \pm 4.9$ & $181 \pm 9.5$ & $180 \pm 9.1$ & $185 \pm 11.2$ \\
\hline Ethanol $(200 \mathrm{mg} / \mathrm{kg})$ & $172 \pm 9.5$ & $173 \pm 8.4$ & $179 \pm 9.5$ & $183 \pm 5.6$ & $176 \pm 7.5$ \\
\hline Ethanol (400 mg/kg) & $165 \pm 7.2$ & $169 \pm 13.5$ & $160 \pm 10.5^{* * *}$ & $157 \pm 10.0$ & $154 \pm 5.3$ \\
\hline Aqueous (100 mg/kg) & $162 \pm 9.8$ & $169 \pm 6.4$ & $162 \pm 14.3^{* *}$ & $158 \pm 12.3$ & $153 \pm 8.0$ \\
\hline Aqueous (200 mg/kg) & $174 \pm 4.7$ & $177 \pm 8.5$ & $160 \pm 10.4^{* * *}$ & $173 \pm 5.4$ & $166 \pm 11.8$ \\
\hline Aqueous (400 mg/kg) & $170 \pm 9.4$ & $173 \pm 5.7$ & $166 \pm 11.3^{*}$ & $164 \pm 12.7$ & $160 \pm 10.0$ \\
\hline
\end{tabular}

Statistical analysis of data was carried by one-way ANOVA followed by Tukey's Multiple Range Test. The values are mean \pm SD for each group ( $n=6$ ). $P$ value less than 0.05 was considered significant. Pet. Ether: Petroleum ether. $* * * P<0.001, * * P<0.01, * P<0.05$.

(Figure 2C1) showed back to its normal position and apparently, normal sinusoids and less in the number of degeneration of hepatic cells with distorted nuclei and mild inflammation somewhere. The groups treated with the extracts at a dose of 200 and $400 \mathrm{mg} / \mathrm{kg}$ showed gradual improvement in parenchyma and portal inflammation. The aqueous and ethanol extracts showed effective results in maintaining the cellular structure with mildly inflamed hepatocytes and returned the cellular arrangement surrounding the central vein and minimised necrosis when compared to the positive control group (Figure 2D1-2I1).

\section{Kidney}

Histopathological sections of the normal group (Figure 2A2) showed tubular epithelium cells in a well-arranged manner. Kidney sections of the insulin-resistance diabetic rats (Figure 2B2) showed tubular damage, proteinuria and haemorrhage. Haemorrhage is seen within the Bowman's space due to its damage to the glomerular part. The cell cytoplasm is entirely warned out; the nucleolus is pyknotic in nature and lumen of tubule shown cell debris. Diabetic kidneys showed a mild increase in mesangial cells. The standard-treated group 
Liver
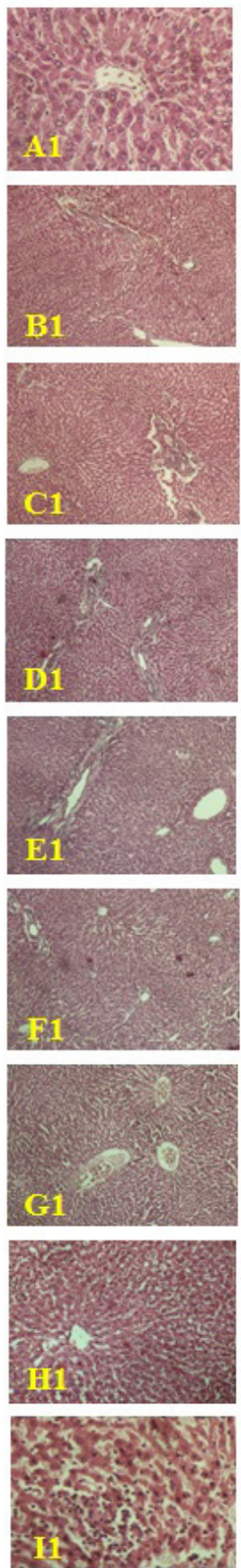

Kidney
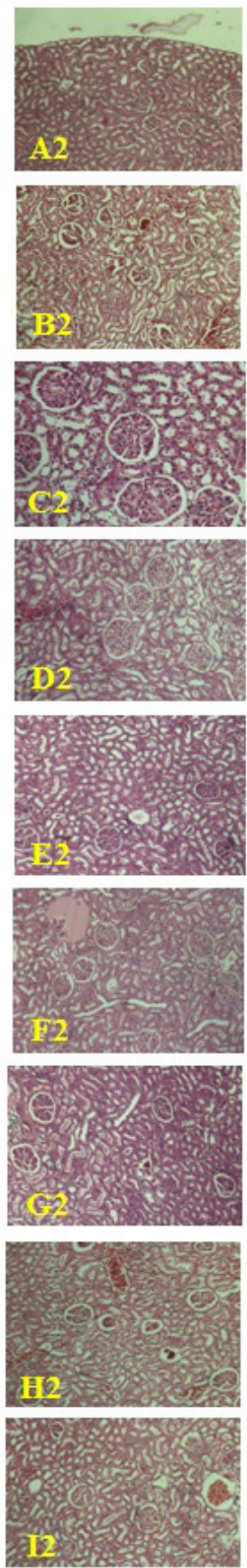

Heart
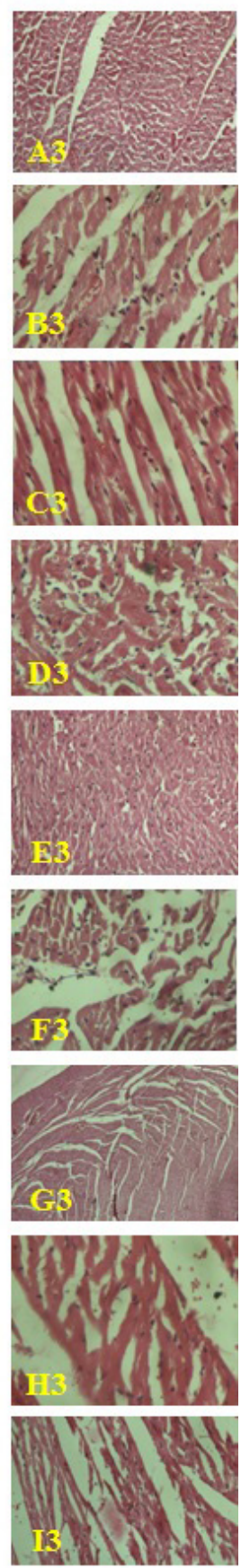

Figure 2: Effect of Plumeria obtusa leaves extracts on histopathological changes of liver, kidney and heart in insulinresistance diabetic rats. A) Normal control, B) Positive control, C) Metformin, D) Petroleum ether extract $(200 \mathrm{mg} / \mathrm{kg})$, E) Petroleum ether extract (400 $\mathrm{mg} / \mathrm{kg})$, F) Ethanol extract (200 $\mathrm{mg} / \mathrm{kg}$ ), G) Ethanol extract (400 mg/kg), H) Aqueous extract $(200 \mathrm{mg} / \mathrm{kg})$ and I) Aqueous extract $(400 \mathrm{mg} / \mathrm{kg})$.

(Figure 2C2) showed marked recovery and brought back to its normal position. Our results indicated that groups treated with the extracts at a dose of 200 and $400 \mathrm{mg} / \mathrm{kg}$ showed drastic improvement in the recovery of damaged tubules. Damaged cells showed a pyknotic nucleolus on the $45^{\text {th }}$ day. The ethanol and aqueous treated-group showed development in the reformation of glomeruli. Tubules with mild proteinuria and less haemorrhage were seen (Figure 2D2-2I2).

\section{Heart}

The histopathology of normal heart tissue (Figure 2A3) revealed the internal structure of the heart, which showed normal myocardial cells with proper nuclei and cytoplasm at their original position. The section of the insulin-resistance diabetic rat heart (Figure 2B3) showed damaged myocardial cells with inflammation, as well as irregular cytoplasm and nuclei. The diabetic heart tissue showed an increase in haemorrhage and cardiomyopathy that could be attributed to the hyperglycaemias due to formation of free radicals, which induce changes in tissues along with cardiomyopathy. The standard-treated group (Figure 2C3) depicted the recovery of heart with apparently normal myocardial cells and less haemorrhage compared to the positive control group. Heart tissues treated with the extracts at a dose of 200 and $400 \mathrm{mg} /$ $\mathrm{kg}$ showed partial recovery with few damaged cells and lesser inflammation. They also showed moderate to mild necrotic conditions. The ethanol and aqueous extracttreated group showed maximum recovery of cells with less inflamed conditions and reformation of myocardial cells and valves (Figure 2D3-2I3).

\section{Scanning electron microscopy Bone}

The epiphyseal edges of the distal femur bone were observed at higher magnification $(\times 500)$ to study the resorption pattern on the surface of the bone. The extensive resorption was seen in the positive control group (Figure 3B1) when compared to normal rat bone (Figure 3A1). The photomicrographs demonstrated a decreased number of resorptive pits per square centimeter in the standard-treated group (Figure 3C1). Among treated groups (Figure 3D1-3I1), ethanol and aqueous extract-treated group showed clearly that the surface of the bone returned to its normal position, which improved the integrity of the bone surface. The ethanol and aqueous extract-treated group reduced, to some extent, the porosity caused by erosion of the minerals at the bone surface. Demineralization activity of dexamethasone can be treated with ethanol and aqueous extracts, which in turn cause remineralization of bones.

\section{Brain}

The ependymal surface of the brain showed non-ciliated zones on the basis of the absence of cilia on the luminal surface of ependymal cells. Scanning electron microscopy showed an indication of tight junction creation between the endothelial cells and few pinocytic vesicles 


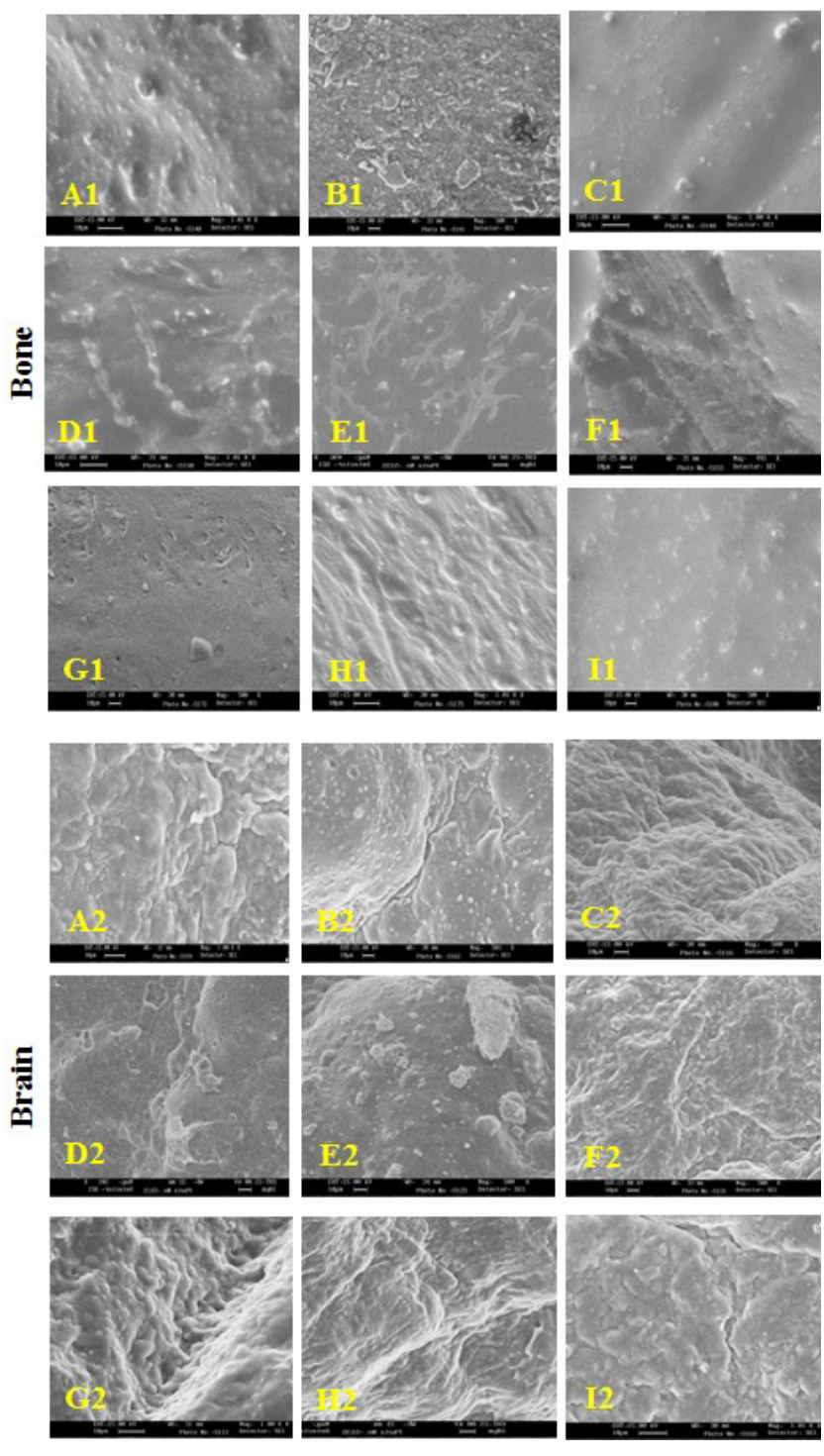

Figure 3: Effect of Plumeria obtusa leaves extracts on ultrastructural changes of bone and brain in insulinresistance diabetic rats. A) Normal control, B) Positive control, C) Metformin, D) Petroleum ether extract (200 mg/kg),

E) Petroleum ether extract (400 mg/kg), F) Ethanol extract (200 $\mathrm{mg} / \mathrm{kg}$ ), G) Ethanol extract (400 mg/kg), H) Aqueous extract $(200 \mathrm{mg} / \mathrm{kg}$ ) and I) Aqueous extract $(400 \mathrm{mg} / \mathrm{kg})$.

(Figure 3A2). In the insulin-resistance diabetic control group (Figure 3B2), the size of resorption pits was very small compared to the normal control group. On the other hand, the surface of the apical membrane was more or less covered by thick microvillus-like structures in the standard-treated group (Figure 3C2). Minor spherical to prolonged protrusions were abundant. The surface of the convex apical membranes was found as filiform and thick microvillus-like structures. The existence of small spherical protrusions was infrequent. Further, isolated epiplexal cells showed rounded or elongated bodies with filiform-like structures and the processes, which form ruffled membranes (Figure 3D2 and 3E2). The areas around each cellular projections were found deeper and electron-dense, which in fact corresponds to the junction sites between the adjacent cells over the luminal surface of its lateral walls, which generally exists as united by a junctional complex (Figure $3 \mathrm{~F} 2$ and $3 \mathrm{H} 2$ ). The resorption pits are brought back to their normal position with tight junctions (Figure 3G2 and 3I2). In ethanol and aqueous extract-treated group (200 mg/ $\mathrm{kg}$ and $400 \mathrm{mg} / \mathrm{kg}$ ), the resorption pits were very prominent, strong and the size was large in nature.

\section{DISCUSSION}

In the insulin-resistance diabetic rat model, dexamethasone is generally used because of its selective $\beta$-cell cytotoxicity and can induce hyperinsulinaemia and hyperglycaemia. It can also interfere with cellular metabolic oxidative mechanisms. Subcutaneous administration of dexamethasone efficiently induced insulin-resistance diabetes in normal rats as evidenced by glycosuria, hyperglycaemia, polyphagia, polydipsia and body weight loss compared to the regular rats. ${ }^{25}$ The secretion of glucagon-like peptide 1 is also reduced. The main benefit of dexamethasone is its potential to generate insulin-resistant state in a moderately short period of time. ${ }^{26}$

Family of Plumeria obtusa currently recognized 1500 species divided into about 424 genera. About eight species of Plumeria is available in India. One of the genera is Plumeria obtusa and its species are quite useful in providing therapeutic effects in pathologic manifestations. ${ }^{19,27}$ Some researchers reported that the active constituents available in some species include linalool, geraniol, citral, geraniol, benzyl salicylate and benzyl benzoate. ${ }^{28}$ Siddiqui et al. ${ }^{15}$ isolated various compounds from Plumeria obtusa, including four new triterpenoids and 12 known compounds, which also included eight triterpenoids. Another research reported new iridoid obtusadoids compounds along with eight known compounds including plumieridin A, plumieridine, 1- $\alpha$-plumieride, 15-demethylplumieride and oleanolic acid. ${ }^{20}$ Various pharmacological activities have also been reported related to other species. Despite all comprehensive studies of these species, scarcity about Plumeria obtusa L. extracts for diabetes mellitus is still not available.

The basic mechanism of hyperglycaemia in case of diabetes mellitus is due to the excess hepatic glycogenolysis and gluconeogenesis in addition to the less usage of glucose by the body tissues. ${ }^{29}$ Dexamethasone showed complex metabolic changes i.e., increase in triglyceride levels causes a disparity in lipid metabolism and develops hyperlipidaemia, increase in glucose levels, which in turn 
causes hyperglycaemia and a decrease in food intake subsequently reduces the body weight. ${ }^{30,31}$ Chronic diabetes has been reported to enhance glycosylated haemoglobin level due to prolonged high blood level of glucose, which leads to glycosylation of haemoglobin. ${ }^{32}$ Our study observed that blood glucose levels were constantly reduced after treatment with ethanol and aqueous extract $(200 \mathrm{mg} / \mathrm{kg}$ and $400 \mathrm{mg} / \mathrm{kg}$ ) when compared with the diabetic control group. Similar results of other Plumeria species were also noticed by Yadav and Undale, ${ }^{33}$ however; an opposite result was reported by Merina $e t$ al. ${ }^{34}$ In the present study, the ability of ethanol and aqueous extracts at all tested doses to reduce serum triglycerides is consistent with the findings of Merina et al. ${ }^{34}$ In addition, the same extracts made insulin levels to be comparable to normal levels. Glycosylated haemoglobin is generally considered as a key test for diagnosing diabetes mellitus and is an authentic indicator in assessing the therapeutic efficacy. The formation of glycosylated haemoglobin is a continuous process wherein the glucose molecules are added to the haemoglobin beta-chain by covalent bonding in an irreversible manner over a period of time. ${ }^{35}$ In the present findings, both ethanol and aqueous extracts showed greater reduction in the percentage of glycosylated haemoglobin on the $45^{\text {th }}$ day.

The Anthropometric parameter is also one of the important concerns related to diabetes. In the case of body weight, both aqueous extracts and the highest dose of ethanol extract showed significant changes in body weight only on the $14^{\text {th }}$ day. This parameter is a wellknown marker of diabetes in both human and animal models. ${ }^{36}$

Regarding the histopathological examinations, the ethanol and aqueous extracts showed excellent results in maintaining the cellular structure of the liver, kidney and heart as they brought them back to their original cellular arrangement when compared with the positive control group. In the same way, scanning electron microscopy showed clearly that the bone surface was returned to its normal position along with improvement in its intactness and integrity by the treatment with ethanol and aqueous extracts. The ependymal surface of the brain showed prominent thick, dense resorption pits in the ethanol and aqueous extract-treated group compared to the positive control group. The groups treated with the ethanol and aqueous extracts at a dose of 200 and 400 $\mathrm{mg} / \mathrm{kg}$ showed excellent improvement in rat brain when viewed by scanning electron microscopy.

Generally, a multifunctional mechanism may involve in the management of diabetes mellitus. In our study, this effect comes out due to many different constituents.
The first mechanism may be due to the presence in this plant higher flavonoids, which have the potential to activate the receptor on the cytoplasm side of the membrane. ${ }^{37}$ It phosphorylates itself with the help of ATP and experiences a spatial arrangement and starts via G-proteins, which liberate several second messengers, protein P-kinases, which open a $\mathrm{Ca}^{2+}$ influx giving an insulin-like effect. ${ }^{38}$ It can also reduce hepatic glucose formation and improve tyrosine phosphorylation of the insulin receptor and insulin receptor substrate similar to insulin. On the other hand, it can also reduce phosphoenolpyruvate carboxykinase gene expression in a phosphoinositide 3-kinase-dependent manner and mimics insulin by increasing PI3K and MAP kinase. ${ }^{39}$

The second most important probable mechanism involved could be because of the alkaloids, which can inhibit mitochondrial function that improves the AMP/ATP ratio, which is also related to the activation pathway helps in curing diabetes. ${ }^{40}$ The other possible mechanism is due to PPAR receptors family; PPAR $\gamma$ stimulation in adipose tissues can leads to development of insulin sensitivity and PPAR $\alpha$ stimulation in the liver produces the reduction in circulating lipid levels. It is described that such effects could be because of the regulation of mRNA expression levels of target genes of PPARs. ${ }^{41,42}$ On the other side, iridoid glycosides are also present, reducing the oxidative stress produced by AGE/AGE receptor signalling pathway via ameliorating AGE clearance and renal AGE receptor expression. ${ }^{43}$ Moreover, oleanolic acid, a triterpenoid found in Plumeria obtusa, is known to have anti-diabetic effects. ${ }^{44}$ Therefore, it is possible that these compounds may prevent insulin resistance and reduce the stress on glucose levels via multiple mechanisms pathways.

\section{CONCLUSION}

The current study clarifies the effects of petroleum ether, ethanol and aqueous extracts of Plumeria obtusa leaves on glucose, glycosylated haemoglobin and insulin levels, as well as lipid profiles to prevent insulin-resistance diabetes mellitus in rats. However, further future studies are required to explore more detailed mechanisms of this plant.

\section{ACKNOWLEDGEMENT}

The authors thank the management of M.M. University (Deemed to be University), Mullana, Ambala, Haryana for the support to complete this study. The authors also thanks the Department of Pathology, M. M. Institute of Medical Science and Research, M.M. University 
(Deemed to be University), Mullana, Ambala, Haryana, for providing the histopathology and microscopic studies.

\section{CONFLICT OF INTEREST}

The authors declare no conflicts of interest.

\section{ABBREVIATIONS}

AGE: Advanced glycation end-product; JNK: C-Jun-Nterminal kinases; SAPK: Stress activated protein kinase; NF- $\boldsymbol{x}$ B: Nuclear factor kappa-light-chain enhancer of activates B cells; P38 MAPK: p38 MAP kinase; PI3K: phosphatidylinositide 3-kinase; AMP: Adenosine monophosphate pathway; ATP: Adenosine tri phosphate; PPAR $\boldsymbol{\gamma}$ : Peroxisome Proliferator-activated receptor gamma; mRNA: Messenger ribo nucleic acid.

\section{REFERENCES}

1. Nolan CJ, Prentki M. Insulin resistance and insulin hypersecretion in the metabolic syndrome and type 2 diabetes: Time for a conceptual framework shift. Diab Vasc Dis Res. 2019;16(2):118-27.

2. Acharjee $S$, Ghosh B, Al-Dhubiab BE, Nair AB. Understanding type 1 diabetes: Etiology and models. Can J Diabetes. 2013;37(4):269-76.

3. Jeong E, Park N, Kim Y, Jeon JY, Chung WY, Yoon D. Temporal trajectories of accompanying comorbidities in patients with type 2 diabetes: A Korean nationwide observational study. Sci Rep. 2020;10(1):5535.

4. Nair AB, Gupta S, AI-Dhubiab BE, Jacob S, Shinu P, Shah J, et al. Effective therapeutic delivery and bioavailability enhancement of pioglitazone using drug in adhesive transdermal patch. Pharmaceutics. 2019;11(7):359.

5. Williams R, Karuranga S, Malanda B, Saeedi P, Basit A, Besançon S, et al. Global and regional estimates and projections of diabetes-related health expenditure: Results from the International Diabetes Federation Diabetes Atlas, $9^{\text {th }}$ edition. Diabetes Res Clin Pract. 2020;162:108072.

6. Gupta S, Nair A, Jhawat V, Mustaq N, Sharma A, Dhanawat M, et al. Unwinding Complexities of Diabetic Alzheimer by Potent Novel Molecules. Am J Alzheimers Dis Other Demen. 2020;35:1533317520937542.

7. Geer EB, Islam J, Buettner C. Mechanisms of glucocorticoid-induced insulin resistance: Focus on adipose tissue function and lipid metabolism. Endocrinol Metab Clin North Am. 2014;43(1):75-102.

8. Yaribeygi H, Sathyapalan T, Atkin SL, Sahebkar A. Molecular Mechanisms Linking Oxidative Stress and Diabetes Mellitus. Oxid Med Cell Longev. 2020;8609213.

9. Haeusler RA, McGraw TE, Accili D. Biochemical and cellular properties of insulin receptor signalling. Nat Rev Mol Cell Biol. 2018;19(1):31-44.

10. Okechukwu PN, Ekeuku SO, Sharma M, Nee CP, Chan HK, Mohamed N, et al. In vivo and in vitro antidiabetic and antioxidant activity of spirulina. Phcog Mag. 2019;15(62):17-29.

11. Governa P, Baini G, Borgonetti V, Cettolin G, Giachetti D, Magnano AR, et al. Phytotherapy in the Management of Diabetes: A Review. Molecules. 2018;23(1):105

12. Sharma A, Gupta S, Chauhan S, Nair A, Sharma P. Astilbin: A promising unexplored compound with multidimensional medicinal and health benefits. Pharmacol Res. 2020;158.

13. Gupta S, Mehla K, Chauhan D, Kumar S, Nair A. Morphological changes and Antihyperglycemic effect of $M$. champaca leaves extract on Beta-cell in alloxan induced diabetic rats. Recent Res Sci Technol. 2011;3(1):81-7.

14. Devprakash TR, Gurav S, Kumar G, Mani TT. An review of phytochemical constituents and pharmacological activity of Plumeria species. Int J Curr Pharm Res. 2012;4(1):1-6.
15. Siddiqui BS, llyas F, Rasheed M, Begum S. Chemical constituents of leaves and stem bark of Plumeria obtusa. Phytochemistry. 2004;65(14):2077-84.

16. Dhandapani S, Jin J, Sridhar V, Chua NH, Jang IC. CYP79D73 Participates in Biosynthesis of Floral Scent Compound 2-Phenylethanol in Plumeria rubra. Plant Physiol. 2019;180(1):171-84.

17. Kadébé ZT, Metowogo K, Bakoma B, Lawson-Evi SP, Eklu-Gadegbeku K, Aklikokou K, et al. Antidiabetic activity of Plumeria alba Linn (apocynaceae) root extract and fractions in streptozotocin-induced diabetic rats. Tropical Journal of Pharm Res. 2016;15(1):87-94.

18. Zoua K, Batomayena B, Kossi M, Lawson-Evi P, Kwashie E, Kodjo A, et al. Effects of Plumeria alba Roots Hydro Alcoholic Extract on some Parameters of Type 2 Diabetes. Res J Med Plant. 2014;8:140-8.

19. Semenya S, Potgieter M, Erasmus L. Ethnobotanical survey of medicinal plants used by Bapedi healers to treat diabetes mellitus in the Limpopo Province, South Africa. J Ethnopharmacol. 2012;141(1):440-5.

20. Saleem M, Akhtar N, Riaz N, Ali MS, Jabbar A. Isolation and characterization of secondary metabolites from Plumeria obtusa. J Asian Nat Prod Res. 2011;13(12):1122-7.

21. Gupta S, Hrishikeshvan HJ, Sehajpal PK. Spirulina protects against rosiglitazone induced osteoporosis in insulin resistance rats. Diabetes Res Clin Pract. 2010;87(1):38-43.

22. Nair A, Morsy MA, Jacob S. Dose translation between laboratory animals and human in preclinical and clinical phases of drug development. Drug Dev Res. 2018;79(8):373-82.

23. Anroop B, Bhatnagar S, Ghosh B, Parcha V. Studies on Ocimum gratissimum seed mucilage: Evaluation of suspending properties. Indian J Pharm Sci. 2005;67(2):206

24. Gupta S, Mehla K, Chauhan D, Nair A. Anti-inflammatory activity of leaves of Michelia champaca investigated on acute inflammation induced rats. Lat Am J Pharm. 2011;30(4):819.

25. Gupta A, Al-Dhubiab BE, Chattopadhyaya I, Nair A, Kumria R, Gupta S. Assessment of pharmacokinetic interaction of spirulina with glitazone in a type 2 diabetes rat model. J Med Food. 2013;16(12):1095-100.

26. Gounarides JS, Korach-André M, Killary K, Argentieri G, Turner O, Laurent D. Effect of dexamethasone on glucose tolerance and fat metabolism in a dietinduced obesity mouse model. Endocrinology. 2008;149(2):758-66.

27. Ali N, Junaid M, Ahmad D, UrRahman M, Ali N, Katzenmeier G. Antibacterial and antifungal activity of solvent extracts from Plumeria obtusa Linn. Trop Biomed. 2014;31(4):607-15.

28. Tohar N, Awang K, Mohd MA, Jantan I. Chemical composition of the essential oils of four Plumeria species grown on Peninsular Malaysia. J Essent Oil Res. 2006;18(6):613-7.

29. Jacob S, Morsy MA, Nair A. An overview on the insulin preparations and devices. Indian J Pharm Educ Res. 2018;52(4):550-7.

30. Arab DA, Mahboubi M. A study of the influence of dexamethasone on lipid profile and enzyme lactate dehydrogenase. J Med Life. 2015;8(Spec Iss 3):72-6.

31. Jahng JW, Kim NY, Ryu V, Yoo SB, Kim BT, Kang DW, et al. Dexamethasone reduces food intake, weight gain and the hypothalamic 5-HT concentration and increases plasma leptin in rats. Eur J Pharmacol. 2008;581(1-2):64-70.

32. Kandhare AD, Rais N, Moulick N, Deshpande A, Thakurdesai P, Bhaskaran $S$. Efficacy and safety of herbal formulation rich in standardized fenugreek seed extract as add-on supplementation in patients with type 2 diabetes mellitus on sulfonylurea therapy: A 12-week, randomized, double-blind, placebo-controlled, multi-center study. Pharmacogn Mag. 2018;14(57):393.

33. Yadav A, Undale V. Antidiabetic effect of Plumeria rubra linn. in streptozotocin induced diabetic rats. Int J Pharm Sci Res. 2017;8(4):1806.

34. Merina AJ, Sivanesan D, Begum VH, Sulochana N. Antioxidant and hypolipidemic effect of Plumeria rubra L. in alloxan induced hyperglycemic rats. J Chem. 2010;7(1):1-5.

35. Leow MK. Glycated Hemoglobin (HbA1c): Clinical Applications of a Mathematical Concept. Acta Inform Med. 2016;24(4):233-8.

36. Suman RK, Ray MI, Borde MK, Maheshwari U, Deshmukh YA. Development of an Experimental Model of Diabetes Co-Existing with Metabolic Syndrome in Rats. Adv Pharmacol Sci. 2016;9463476.

37. Soares JMD, Leal AEBP, Silva JC, Almeida JR, DeOliveira HP. Influence of flavonoids on mechanism of modulation of insulin secretion. Pharmacogn Mag. 2017;13(52):639. 
38. Wootten D, Simms J, Koole C, Woodman OL, Summers RJ, Christopoulos A, et al. Modulation of the glucagon-like peptide-1 receptor signaling by naturally occurring and synthetic flavonoids. J Pharmacol Exp Ther. 2011;336(2):540-50.

39. Eid HM, Nachar A, Thong F, Sweeney G, Haddad PS. The molecular basis of the antidiabetic action of quercetin in cultured skeletal muscle cells and hepatocytes. Pharmacogn Mag. 2015;11(41):74.

40. Hardie DG. AMP-activated/SNF1 protein kinases: Conserved guardians of cellular energy. Nat Rev Mol Cell Biol. 2007;8(10):774-85.

41. Jia Y, Bhuiyan MJ, Jun HJ, Lee JH, Hoang MH, Lee HJ, et al. Ursolic acid is a PPAR- $\alpha$ agonist that regulates hepatic lipid metabolism. Bioorg Med Chem Lett. 2011;21(19):5876-80.
42. Goto T, Takahashi N, Hirai S, Kawada T. Various Terpenoids Derived from Herbal and Dietary Plants Function as PPAR Modulators and Regulate Carbohydrate and Lipid Metabolism. PPAR Res. 2010;483958.

43. Yamabe N, Kang KS, Matsuo Y, Tanaka T, Yokozawa T. Identification of antidiabetic effect of iridoid glycosides and low molecular weight polyphenol fractions of Corni Fructus, a constituent of Hachimi-jio-gan, in streptozotocininduced diabetic rats. Biol Pharm Bull. 2007;30(7):1289-96.

44. Sen A. Prophylactic and therapeutic roles of oleanolic acid and its derivatives in several diseases. World J Clin Cases. 2020;8(10):1767-92.

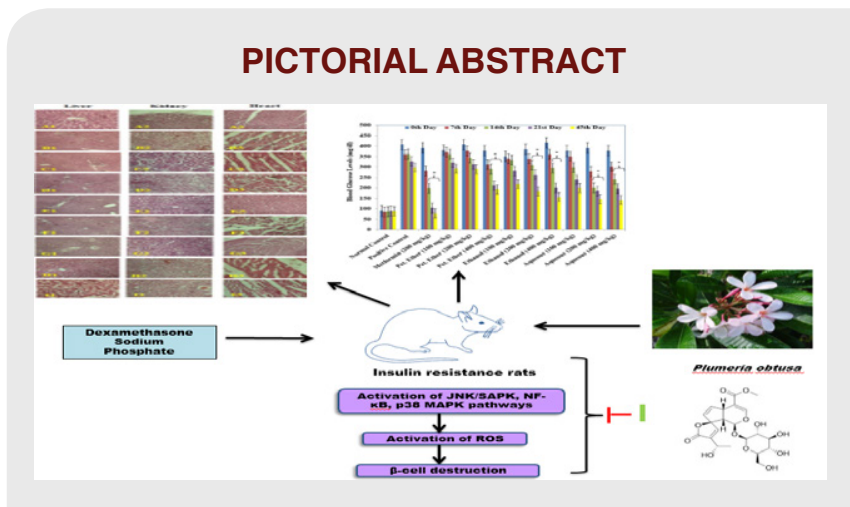

\section{SUMMARY}

- Unexplored traditional plant.

- Ethanol and aqueous extracts showed remarkable results in reduction of blood glucose, cholesterol and for prevention in complications of diabetes.

- Proof of evidence showed improvement in the organs after treated with extracts.

- Improvement as anti-diabetic effect due to presence of flavonoids and glycosides.

- This work is helpful for molecular mechanistic study also.

\section{About Authors}

Dr Sumeet Gupta working as Dean \& Principal, M. M. College of Pharmacy, M. M. University (NAAC "A" grade Deemed University), Mullana, Ambala, Haryana. He was awarded the degree of Doctor of Philosophy (Ph.D) under the faculty of Pharmaceutical Sciences, Guru Nanak Dev University, Amritsar. Areas of his research interest include the pharmacogenomics, pharmacoepidemiology and prevalence studies of metabolic syndrome. Dr Sumeet has more than 16 years of teaching and research experience in the area of "Preclinical and Clinical Pharmacology". He has published various research \& review articles with high thomson ruter impact factor in peer review National and International Journals. He has also published 2 books and one chapter with International Publishers. He has guided more than $40 \mathrm{M}$ Pharm and $3 \mathrm{PhDs}$. Currently, $5 \mathrm{Ph}$.D students and $4 \mathrm{M}$ Pharm research scholars are working under his supervision. He was received Bursary Award by Elsevier publishers, United Kingdom for his best nutraceutical research in Pharm-nutrition conference. Additionally he has received International support travel grant from centre for International Co-operation in Science. He is also the member of reviewer of many reputed scientific international journals like Pharmaceutical Biology, International $\mathrm{J}$ of Diabetes in Developing countries, $\mathrm{J}$ of Publish health, Current Pharmaceutical Design, Current Drug Therapy and Natural Product Research.

Cite this article: Gupta S, Sharma H, Morsy MA, Nair AB, Kaur K, Kumar S, Dhanawat M. Protective Effect of Plumeria obtusa Leaves Extracts on Dexamethasone-induced Insulin-resistance Diabetes Mellitus in Rats. Indian J of Pharmaceutical Education and Research. 2021;55(1s):s184-s192. 